\title{
Covid-19 in Vulnerable Population and Measures of Prevention
}

\author{
Shivangi Jain ${ }^{1}$, Dr. Swaroopa Chakole ${ }^{2}$ \\ ${ }^{1}$ Intern, Dept. of Community Medicine, Jawaharlal Nehru Medical College, Datta Meghe Institute of Medical \\ Sciences (Deemed to be University), Sawangi (Meghe), Wardha-442001, Maharashtra, India \\ ${ }^{2}$ Professor, Dept. of Community Medicine, Jawaharlal Nehru Medical College, Datta Meghe Institute of \\ Medical Sciences (Deemed to be University), Sawangi (Meghe), Wardha-442001, Maharashtra, India \\ Email: ${ }^{1}$ shivangijain10@yahoo.in, ${ }^{2}$ drswaroopachakole@gmail.com \\ Corresponding author's name and address: Dr. Swaroopa Chakole, Department of Community Medicine, \\ Acharya Vinoba Bhave Rural Hospital, Datta Meghe Institute of Medical Sciences (DU). \\ Corresponding author's email id: drswaroopachakole@gmail.com
}

Type of Article: Review

Conflict of Interest: None

Funding: DMIMS

Ethical Approval: IEC, DMIMS, Wardha.

\section{ABSTRACT \\ BACKGROUND}

COVID-19 or coronavirus disease 2019 is the most lethal disease outbreak of the century. Casualties include certain section of population which are vulnerable to the disease due to their weak immune system response.

\section{SUMMARY}

Certain section of the population is more susceptible to develop more critical illness outcome than their other counterparts. These vulnerable people includes elders, pregnant women, infants, people with underlying health problems and so many other people. Targeted approach towards these group in terms of safeguarding them from the infection may prove to be beneficial in overall containment measures.

\section{CONCLUSION}

Preventive measures are the best suited containment measures for disease like COVID-19 which has not only short term but has long term implications. Dedicated study might reveal a more nuanced approach for the same.

KEYWORDS:Covid-19, Comorbidity, Preventive Measures, Diabetes Obesity, Infodemic, Pregnant Women.

\section{INTRODUCTION}

Novel coronavirus is the virus that causes the Coronavirus disease 2019 or COVID19. The crown shaped virus has been creating ruckus all over the world stalling all the activities one way or the other. The lethal nature of the pandemic makes it more deadly and fearful.(1) Also the extreme virulent nature of the pandemic has also created roadblocks in containment plans. After the origination of the first few cases in Wuhan city of the Hubei province of china, it has then spread through various parts of the globe and affecting billions of people. As of January 04, 2020, $85,180,344$ infection cases of COVID-19 are recorded from more than 200 countries and case fatalities stands at 1,844,518(2). This indicates the high virulent nature and huge

spreading ability of the virus and along with deadly nature which proved by case fatalities crossing one million mark and approaching to double of the figure. Major countries affected are United States of America, India, Brazil, Russianfederation, France and United Kingdom(3). These countries only accounts for more than half of the infection cases reported and case fatalities around the world. Recent news of emergence of new mutated viral strain of the coronavirus from United Kingdom(4) and South Africa(5) was followed by closure of air services from and to these countries as learning from past 
experiences. These huge casualties are also linked with the infected patients underlying medical condition and age group(6). Underlying medical condition or comorbidity is the biggest decider in the clinical outcomes of the COVID-19 infected patients. COVID-19 impacts differentially on different section of the society. Some sectionof the society are more vulnerable than other and can be affected more. These includes elderlies, pregnant women, comorbid patients, underprivileged community and many more(7). These sections most accounts for the overall infection rate and mortalities. If these section is secured from the infection then the numbers related to COVID-19 may change for good. Also long term implications are bound to arise and necessary steps must be taken today to tackle the future problems. Preventive measures are the best way to deal with the infection like COVID-19 pandemic. All these points will comprehensively analyzed and overviewed in this article.

\section{COVID-19 AND VULNERABLE SECTIONS}

Coronavirus disease 2019 or COVID-19 has already extended its stay on earth and entered in 2021. The new strain of the mutated coronavirus has proved the notoriety of the coronavirus of being mutate in several different strain. More than a year since its inception in China, still the virus behavior is highly unpredictable and uncertain. The new mutated strain adds only to the woes. The virus has impacted and still is impacting the society has a whole differentially. Certain section of the human population has been found to be extremely vulnerable in getting infected by COVID-19. Moreover these section of the human populace have shown to be producing negative clinical outcomes post treatment. These vulnerable section who have greater chance developing severe clinical outcome post COVID-19 infection includes, persons with comorbidities, pregnant women, old aged people, infants and new born babies, LGBTQ+ community, poor and homeless people, differently abled people, refugees and displaced people due to various reasons. Each group from previously mentioned vulnerable sections have various medical conditions and each have its own response generated by their bodies. The case fatalities due to COVID19 infection has crossed one million mark which is a big cause of concern. Majority of the casualties are attributed to comorbid patients getting contracted by the infection, elderlies with age more than 60 years and other sections. Proper study is needed in order to design the mitigation measures across countries. If we are successful in curbing infection among these vulnerable section, overall infection rate as well as case fatality rate will reduce drastically benefitting the containment efforts. Targeted efforts among these section may have positive ripple effects and can generate multiple affirmative outcomes(8).

\section{COVID-19 AND COMORBIDITIES}

COVID-19 has become most deadly disease that has struck the humanity since last 100 years. The reason behind its deadly and extremely lethal nature is having its connection with weak immune response of infected person. The weak immune response of the infected person can be attributed to various medical conditions that are already attached to the infected person before the infection. Various underlying conditions weakens the bodily response of the person due to various internal stresses that are attached to the medical condition(9). Various underlying medical condition or comorbidity includes heart ailments, liver cirrhosis, renal failure, obesity, diabetes, compulsory obstructive pulmonary disorder (COPD) and various such chronic illnesses are associated with worsening the clinical outcome if patient is being treated for COVID-19. The comorbidity 
irrespective of age group can affect any person and which can be genetically inherited or acquired on due course of life. Among these illnesses diabetes is supposed to be the worst underlying medical condition to have with the COVID-19 infection. The diabetic patient have extremely high chance of developing severe clinical outcomes and may prove fatal if not treated and diagnosed at early stages. Diabetes does not grow alone and it invites other diseases like hypertension, renal ailments, disturbance in blood glucose levels, increased susceptibility to cardiac injury due to disturbed blood glucose levels, dysregulated immune response. Also administration of diabetes drugs may hinder in the COVID-19 treatment course. A Chinese study shows that in a particular province prevalence of diabetes was 7.4 percent while in the COVID-19 infected patients the prevalence was over 20 percent which is almost triples the vulnerability of the diabetic patient. Also diabetes in old aged patients have worse outcome among all the age groups having diabetes. The $\mathrm{d}$ dimer levels linked to high mortality rate was found to be high among diabetic patients(10). Use of mechanical ventilation or oxygen support system was high among COVID-19 infected patients having diabetes as underlying medical condition.Graver picture was revealed when 2003 COVID-19 related fatalities wee assessed. It was found that prevalence of diabetes was double in non-surviving or deceased patients of COVID-19than their surviving counter parts in the countries of China and Italy. This is not came as surprised as previous coronavirus related outbreaks in 2003 and 2012 namely severe acute respiratory syndrome (SARS) and middle eastern respiratory syndrome (MERS) also saw prevalence of diabetes among deceased people(11). The risk of catching infection is not increased merely by having diabetes but if diabetic patient got the COVID-19 infection then the clinical outcome in majority of cases is severe and not on patients side. Type 1 diabetes and type 2 diabetes cases among COVID-19 infection cases and their respective outcomes is not compared perse but observational analysis shows that type 2 diabetes mellitus has been more prevalent among the said patients than the type 1 diabetes mellitus. The negative correlation between administration of the insulin therapy and COVID-19 treatment also makes diabetic patient more vulnerable. Therefore preventive care is suggested in such vulnerable section.

COVID-19 and obesity have also a very destructive impact on the human body. Obesity decided by generally body mass index being greater than 25 and 30 are obese and severely obese patients. Intubation of patients with obesity is a lot harder medical task than any other underlying medical illness. The requirement of shifting the obese patient in case he or she contracts the COVID-19 infection is higher as compared to other illness. Challengesdo not stophere as various radio imaging and thermal and $\mathrm{x}$ ray imaging is not easily possible in case of obese patients. They are more difficult to transport by nursing staff or allied health care workers. Even non-infected obese patients will have impact on their physical as well as mentalhealth as they are not able to move easily during lockdown and movement restrictions resulting into poor health. Inactivity for even short tenure of time can induce metabolic illness caused by inactivity. Junk food is the menace that world was facing before the arrival of the pandemic and after theCOVID-19 pandemic arrival, the situation worsened as more consumption is being done in movement restrictions and due to lockdown. Junk food, food with high fats and sugars are associated with obesity(12).

Elders or old aged persons considered generally after age of 60 years has already lot to face and COVID-19 pandemic has 
only worsened the situation for these groups. There are various subsections in these group as some of the elders have no under lying illnesses but some of them got chronic medical conditions. Mobility affects the most. Multispectral impact can be seen on the elderlies as they are already in their immunosuppressive state making them more vulnerable. Clinical outcomes generally worsens in elderly patient than in other age groups due to previously statedreason. Also psychological impact also cannot be ignored as they are already experiencing loneliness and this makes them more difficult to meet their family and friends during lockdown and movement restrictions measure induced by COVID-19. Risk of getting contracted with COVID-19 infection is directly proportional to age. As age increases of a person the chances of getting infected also increases. Elderliesare often designated as vulnerable group due to same reason. People above 60 to 65 years of age have more chances of developing severe clinical outcomes and therefore there is an increased risk of admitting the patient in intensive care units and ventilator help is needed which indicates deterioration of the condition. Far aged persons ranging from 80 years of age and above have chances of developing severe clinical outcome and possibly death two hundred times higher as compared to others(13).

Pregnant women are already at risk of various infections because they are already supporting another life in them and undergoing immunosuppressive state. They already need regular medical attention and if required intervention to remain healthy and check the infants status. They are certainly at high risk of catching of infection than their nonpregnant counterpart. Especially mothers in their third trimester are more vulnerable than their first two counterparts. Adverse outcome has been seen in infected mothers with COVID-19 such as preterm birth of the child, still birth, pregnancy complications and many more. But these severe outcomes are not attached to COVID-19 directly as study is undergoing. In lockdown the regular medical checkup was hampered by movement restrictions and divergence of resources in the containment of the COVID-19(14). Therefore proper follow up is not present now and many mothers are on the verge of developing severeclinical outcomes. COVID-19 Infected mothers are more worried as they are suspecting vertical transmission of the infection from them to child. As no clear evidence points towards vertical transmission this point may need more evaluation among pregnant women across the globe. But Neonates are getting contracted by infection in many cases. This can also attributed to the lax implementation of hygiene standard and not taking proper precaution while handling the new born baby. During breastfeeding, although little evidence is their of transmission of virus from the milk of mother to the offspring, other surrounding activities such as not wearing mask and gloves while breastfeeding the baby, sneezing and coughing near baby may prove not good as the new born infant is already in weak immune state. If mother is infected with COVID-19 then baby must be kept at sufficient distance from the mother and all precautions must be taken when essential activities like breastfeeding etc. are being carried out. This can surely increases the chance of safeguarding the baby from contracting the infection from surrounding(15).

\section{OTHER VULNERABLE SECTION}

Various other vulnerable sections which are not taken in to account while assessing the impact of the COVID-19. Homeless, poor people, differently abled persons, LGBTQ+ community has their own problems and pandemic madethem worse already. They have limited chance of seeking help. Many of us turned them down on a regular basis even if they are in 
our close proximity. COVID-19 pandemic made their lives more dependent and difficult as seeking medical attention is now much more complicated than before. Also these sections of the society have less awareness about the provisions made for them and are not able to avail them due to lack of knowledge(16). Also some of them have medical conditions which needs special attention like differently abled persons and LGBTO+ community. In case of homeless people, shelter homes are not the ideal place but they are made to stay there due to their poor socioeconomic condition. The raging coronavirus is known for its high virulent nature and congestion in shelter homes may invite another super spreading events so it needs to be looked upon as soon as possible(17).

Psychological impact and the social distress was also widespread among the community as a whole and it was quite under estimates while doing assessment of the impact of the COVID-19 pandemic. As the novel coronavirus brought the disease that was not known before, mitigating measures took time to be formulated and implemented. Till then blanket measures like lockdown and movement restrictions were imposed to curb the spread of the virus and get some hold on the uncontrollable situation. This has resulted in the home confinement situation and no going out was allowed for considerable amount of days. Suddenly people were in their houses with their present family and no other person was allowed to travel to meet their loved ones and family and friends. This was accompanied with the low amount of physical exercise which is necessary to keep up your mood. Constant hearing of huge case fatality rates and new negative news and the parallel Infodemic has also created ruckus. The huge uncertainty attached with the coronavirus disease 2019 or COVID-19 has also induced anxiety about the future course of event. Especially vulnerable section was hard hit as their jobs were taken away and livelihoods were lost in the course of lockdown. This has severely taken toll on mental health of not only ordinary people but also health care professionals who are assigned to deal with containment of the COVID-19 pandemic. They are under constantthreat of not only getting contracted by the disease but also more worried about transmitting the infection to their family members and loved ones unintentionally when they get home. This has already affected their efficiency and mental health. LGBTQ+ community is already facing the heat of the moment in many countries they are evenpunished for who they are. Little percentage of the community has been medically insured and their medical needs are quite often neglected. They face widespread hindrance to access even basic health care and if infected with COVID-19, may have to go through tremendous obstacles(18).

\section{PREVENTIVE MEASURES}

As the above paragraphs discussed about the long term implications and various other clinical outcomes which are not good for the infected patients, it is important to prevent the disease from happening. The lethal nature of COVID-19 has proved that preventive strategy is way better than curative plan as many effects are avoided. All these vulnerable sections if given prioritization inn mitigation measures case fatalities would definitely come down as these are the group contributing maximum to the case fatalities. Also the overall infection cases may also come down as these people are also more vulnerable comparatively. The long term implications of the COVID-19 pandemic is already coming upon and are bound to come up as also was seen in Severe acute respiratory syndrome (SARS) and middle eastern respiratory syndrome (MERS)outbreaks. Therefore it is essential to take preventive steps to prevent the disease from happening at first place. Various measures suggested by World Health Organization 
(WHO) and health authorities across the world. This includes wearing of masks, following physical distancing, wearing personal and protective equipment (PPE) kit, sanitizing hands regularly. This measures are extremely effective in warding off the virus and keep the person infection free if followed with utmost precaution(19). These measures had already been proven to be effective in previous outbreaks of SARS, MERS and Ebola. During Ebola outbreak in African countries,PPE kit enabled health care workers to trace the patient without getting infected by the disease. Usage of prophylactics and balance diet also proven to be very effective in safeguarding oneself from the infection. Vitamin C, Vitamin D, probiotics are extremely helpful in keeping up the body's immune response(20). These substances have antioxidants and antiinflammatory properties which are much needed in the COVID-19 pandemic. It offers very cost effective solution and will help not only in current pandemicsituation but also in future such scenario by keeping body fit for fighting any viral infection. Also controlling the Infodemic is a type of preventive measures as variousconsequential events are averted and which are not good for the society as a whole. Self-medication according to some viral message may prove fatal and must be checked up with the doctor or competent authority(21).A number of related studies were reported from this region (22-24). Useful studies on prevention of spread of infection were reported (25-28). Khatod et. al.(29) and Dhole et. al. (30) discussed on disinfection in dentistry. Late et. al. elaborated on protocol for handling and disposal of the dead bodies in Covid-19 (31).

\section{CONCLUSION}

The situation that currently world is facing is extremely grave and unprecedented. No other disease outbreak was able to cause such widespread damage across the world. These times needs unprecedented measures and targets strategy to deal with the current scenario. Vulnerable section needs to be protected do that they not only saved from the infection but severe outcomes are also affected. The long term implications needed to be studied in detail so that necessary steps can be taken to tackle the viral infection. Preventive measures are more suitable in pandemic like COVID-19 as long term implications are far worse than the treatment. Also several permanent changes can also occur. Psychological impact and social distress can be dealt with sensitization and care. Counsellors and mental health expert along with several other competent authorities can be employed to deal with the queries of people. Future course of the pandemic is really uncertain even after the arrival of the vaccine. Therefore it is important to be protected and to protect others by following the variousguidelines issued time to time by competent authorities. Multiform approach is neededso that the menace can be curbed in less time as more tie means more casualties and more losses. Cooperation from all sections of the society must ensure in order to obtain positive results.

\section{REFERENCES:}

[1] Dushyant Bawiskar, Pratik Phansopkar, Ayurva Vilas Gotmare. COVID-19 Facets: Pandemics, Curse and Humanity. Int J Res Pharm Sci. 2020 Aug 6;11(SPL1):385-90.

[2] COVID-19 Map [Internet]. Johns Hopkins Coronavirus Resource Center. [cited 2021 Jan 4]. Available from:

https://coronavirus.jhu.edu/map.html

[3] WHO Coronavirus Disease (COVID19) Dashboard [Internet]. [cited 2021 Jan 4]. Available from: https://covid19.who.int 
[4] Wise J. Covid-19: New coronavirus variant is identified in UK. BMJ [Internet]. 2020 Dec 16 [cited 2020 Dec 23];371:m4857. Available from: https://www.bmj.com/content/371/b mj.m4857

[5] CDC. Coronavirus Disease 2019 (COVID-19) [Internet]. Centers for Disease Control and Prevention. 2020 [cited 2021 Jan 3]. Available from:

https://www.cdc.gov/coronavirus/20 19-ncov/more/scientific-briefemerging-variant.html

[6] Guan W-J, Liang W-H, Zhao Y, Liang H-R, Chen Z-S, Li Y-M, et al. Comorbidity and its impact on 1590 patients with COVID-19 in China: a nationwide analysis. Eur Respir J. 2020;55(5).

[7] Yan J, Guo J, Fan C, Juan J, Yu X, Li J, et al. Coronavirus disease 2019 in pregnant women: a report based on 116 cases. Am J Obstet Gynecol [Internet]. $2020 \mathrm{Jul} 1$ [cited 2020 Oct 17];223(1):111.e1-111.e14.

Available from: https://www.ajog.org/article/S00029378(20)30462-2/abstract

[8] COVID-19 Rehabilitation in Vulnerable Populations [Internet]. Physiopedia. [cited 2021 Jan 3]. Available from: https://www.physiopedia.com/COVID-

19_Rehabilitation_in_Vulnerable_Po pulations

[9] Ejaz H, Alsrhani A, Zafar A, Javed $\mathrm{H}$, Junaid $\mathrm{K}$, Abdalla AE, et al. COVID-19 and comorbidities: Deleterious impact on infected patients. J Infect Public Health. 2020 Dec;13(12):1833-9.

[10] Bouhanick B, Cracowski J-L, Faillie J-L, French Society of Pharmacology, Therapeutics (SFPT). Diabetes and COVID-19. Therapie. 2020 Aug;75(4):327-33.

[11] Erener S. Diabetes, infection risk and COVID-19. Mol Metab [Internet].
2020 Sep [cited 2020 Dec 19];39:101044. Available from: https://www.ncbi.nlm.nih.gov/pmc/ar ticles/PMC7308743/

[12] Callender LA, Curran M, Bates SM, Mairesse M, Weigandt J, Betts CJ. The Impact of Pre-existing Comorbidities and Therapeutic Interventions on COVID-19. Front Immunol. 2020;11:1991.

[13] Enriquez M. COVID-19 Strikes the Vulnerable. Hisp Health Care Int [Internet]. 2020 Sep 1 [cited 2021 Jan 3];18(3):122-3. Available from: https://doi.org/10.1177/15404153209 33618

[14] Mullins E, Evans D, Viner RM, O'Brien P, Morris E. Coronavirus in pregnancy and delivery: rapid review. Ultrasound Obstet Gynecol [Internet]. 2020 [cited 2020 Dec 8];55(5):586-92. Available from: https://obgyn.onlinelibrary.wiley.co m/doi/abs/10.1002/uog.22014

[15] Huntley BJF, Huntley ES, Di Mascio D, Chen T, Berghella V, Chauhan SP. Rates of Maternal and Perinatal Mortality and Vertical Transmission in Pregnancies Complicated by Severe Acute Respiratory Syndrome Coronavirus 2 (SARS-Co-V-2) Infection: A Systematic Review. Obstet Gynecol. 2020;136(2):30312.

[16] Kuy S, Tsai R, Bhatt J, Chu QD, Gandhi P, Gupta R, et al. Focusing on Vulnerable Populations During COVID-19. Acad Med J Assoc Am Med Coll. 2020 Nov;95(11):e2-3.

[17] Salerno JP, Williams ND, Gattamorta KA. LGBTQ populations: $\quad$ Psychologically vulnerable communities in the COVID-19 pandemic. Psychol Trauma Theory Res Pract Policy. 2020 Aug;12(S1):S239-42.

[18] Blake H, Bermingham F, Johnson G, Tabner A. Mitigating the Psychological Impact of COVID-19 
on Healthcare Workers: A Digital Learning Package. Int J Environ Res Public Health. 2020 26;17(9).

[19] Allam M, Cai S, Ganesh S, Venkatesan M, Doodhwala S, Song $\mathrm{Z}$, et al. COVID-19 Diagnostics, Tools, and Prevention. Diagnostics [Internet]. 2020 Jun [cited 2020 Dec 16];10(6):409. Available from: https://www.mdpi.com/20754418/10/6/409

[20] Feyaerts AF, Luyten W. Vitamin C as prophylaxis and adjunctive medical treatment for COVID-19? Nutr Burbank Los Angel Cty Calif [Internet]. 2020 [cited 2020 Dec 10];79:110948. Available from: https://www.ncbi.nlm.nih.gov/pmc/ar ticles/PMC7381407/

[21] Solomon DH, Bucala R, Kaplan MJ, Nigrovic PA. The "Infodemic" of COVID-19. Arthritis Rheumatol Hoboken NJ. 2020 Aug 2.

[22] Khatib, M.N., S. Gaidhane, M. Khatib, M. Ahmed, A. Gaidhane, and Z.Q. Syed. "SARS-CoV and SARSCoV-2: Similar Viruses with Different Trajectories." Wutan Huatan Jisuan Jishu 16, no. 5 (2020): 544-48.

[23] Gaidhane, S., N. Khatib, Q.S. Zahiruddin, A. Gaidhane, S. Telrandhe, and P. Godhiwal. "Depression, Anxiety and Stress among the General Population in the Time of COVID-19 Lockdown: A Cross-Sectional Study Protocol." International Journal of Research in Pharmaceutical Sciences 11, no. Special Issue 1 (2020): 360-64. https://doi.org/10.26452/ijrps.v11iSP L1.2726.

[24] Nisargandha, M.A., and S. Dadaraoparwe. "Spread of Coronavirus Disease 2019 (COVID19) during the Lockdown in the Indian Population and Preventive Measures." International Journal of Research in Pharmaceutical Sciences
11, no. Special Issue 1 (2020): 32832.

https://doi.org/10.26452/ijrps.v11iSP L1.2721.

[25] Rajput, D.S. "Evolution, Ayurveda, Immunity, and Preventive Aspects for Emerging Infectious Diseases Such as COVID-19." International Journal of Research in Pharmaceutical Sciences 11, no. Special Issue 1 (2020): 86-93. https://doi.org/10.26452/ijrps.v11iSP L1.2227.

[26] Sharma, D. "Preventive Measures for COVID-19 Health Care Professionals." International Journal of Research in Pharmaceutical Sciences 11, no. Special Issue 1 (2020): 1307-12. https://doi.org/10.26452/ijrps.v11iSP L1.3626.

[27] Deshpande, A.M., and M.A. Deshpande. "Role of Rasayan Churna in Outbreak of COVID-19 as Preventive and Curative Aspect." International Journal of Research in Pharmaceutical Sciences 11, no. Special Issue 1 (2020): 1208-12. https://doi.org/10.26452/ijrps.v11iSP L1.3594.

[28] Deshpande, M.A., and A.M. Deshpande. "Preventive Measures for COVID 19 through Dincharya and Rutucharya Mentioned in Ayurvedic Text." International Journal of Research in Pharmaceutical Sciences 11, no. Special Issue 1 (2020): 239-45. https://doi.org/10.26452/ijrps.v11iSP L1.2705.

[29] Khatod, S., A. Ikhar, P. Nikhade, and K. Khatod. "Preventive Measures for Dental Professionals during Worldwide Emergency COVID-19." International Journal of Research in Pharmaceutical Sciences 11, no. Special Issue 1 (2020): 150-53. https://doi.org/10.26452/ijrps.v11iSP L1.2294. 
[30] Dhole, P.D., V.K. Lohe, R.P. Kadu, S.C. Mohod, M. Meshram, and G.A. Thakare. "Post COVID-19 Protocol of Treatment, Radiologic Examination and Infection Control in Dentistry." International Journal of Research in Pharmaceutical Sciences 11, no. Special Issue 1 (2020): 138489.

https://doi.org/10.26452/ijrps.v11iSP L1.3664.
[31] Late, S.V., H. Keche, V.K. Chimurkar, and V. Anjankar. "Protocol for Handling and Disposal of the Dead Bodies in Covid-19." International Journal of Current Research and Review 13, no. 1 (2021): 7-9. https://doi.org/10.31782/IJCRR.2021 .13102 . 